Published in "New Journal of Chemistry 41(13): 6025-6032, 2017"

which should be cited to refer to this work.

\title{
Laterally stretched polycyclic aromatic hydrocarbons: synthesis of dibenzophenanthroheptaphene and tetrabenzotriphenylenopyranthrene derivatives $\dagger$
}

\author{
Bassam Alameddine, (D)*a Rajamohanan Sobhana Anju, (D) ${ }^{a}$ Suchetha Shetty, (D) \\ Noorullah Baig, (D) ${ }^{a}$ Fakhreia Al-Sagheer, ${ }^{\text {b }}$ Saleh Al-Mousawi ${ }^{b}$ and \\ Titus Andreas Jenny ${ }^{c}$
}

Efficient methods for the synthesis of dibenzophenanthroheptaphene (DBPH) and tetrabenzotriphenylenopyranthrene (TBTP) were developed. As a result, a series of unprecedented derivatives of DBPH $(\mathbf{1} \mathbf{a}-\mathbf{c})$ and TBTP $(\mathbf{2} \mathbf{a}-\mathbf{b})$ were conventionally obtained from the Scholl cyclodehydrogenation reaction of their respective tribenzopentaphene synthons. An alternative convergent synthesis of DBPH is also shown herein. The novel compounds were fully characterized by high-resolution matrix-assisted laser desorption ionization time of flight mass spectrometry (HR-MALDI-TOF-MS), nuclear magnetic resonance (NMR), UV-Vis absorption and emission spectroscopy. In addition, density functional calculations were carried out to gain insight into the structure and electronic properties of these novel molecules, which corroborates the experimental observations

\section{Introduction}

Polycyclic aromatic hydrocarbons (PAHs) are chief candidates for applications in the field of organic materials. ${ }^{1}$ This is due to many features, from which we note their high electron density, versatile synthesis, excellent chemical stability, and superior tendency to self-assemble into ordered structures. ${ }^{2}$ The latter property permits the PAH derivatives to act as one dimensional charge transport materials. ${ }^{3,4}$ Thus, their ability to transport electrons upon interaction with either an electric field or a photon qualifies them to be potential components in optoelectronic devices. ${ }^{5-8}$ Various PAHs with structures ranging from symmetrical planar $^{9,10}$ or contorted ${ }^{11-15}$ to less symmetrical ${ }^{16,17}$ have been synthesized and studied extensively (see Fig. 1 for representative examples).

PAHs have been drawing much prevalent attention lately because they can act as synthons to prepare graphene-related materials using chemical methods instead of the less controllable physical methods. ${ }^{18}$ Several scalable synthetic approaches have been developed to prepare a wide range of PAHs. ${ }^{12,16,19,20}$ Most of these strategies entail an intramolecular oxidative

${ }^{a}$ Department of Mathematics and Natural Sciences, Gulf University for Science and Technology, Kuwait. E-mail: alameddine.b@gust.edu.kw

${ }^{b}$ Chemistry Department, University of Kuwait, Safat, Kuwait

${ }^{c}$ University of Fribourg, Chemin du Musée 9, 1700 Fribourg, Switzerland

$\dagger$ Electronic supplementary information (ESI) available: HR-MS of 1a-c, 2a-b, 9, and $\mathbf{1 0 a}-\mathbf{b},{ }^{1} \mathrm{H}-\mathrm{NMR}$ of $\mathbf{1 c}, \mathbf{2 b}, \mathbf{9}, \mathbf{1 0 a}-\mathbf{b}$, and $\mathbf{1 3 a}-\mathbf{b}$, and UV absorption-emission spectra of 9. See DOI: 10.1039/c7nj00371d
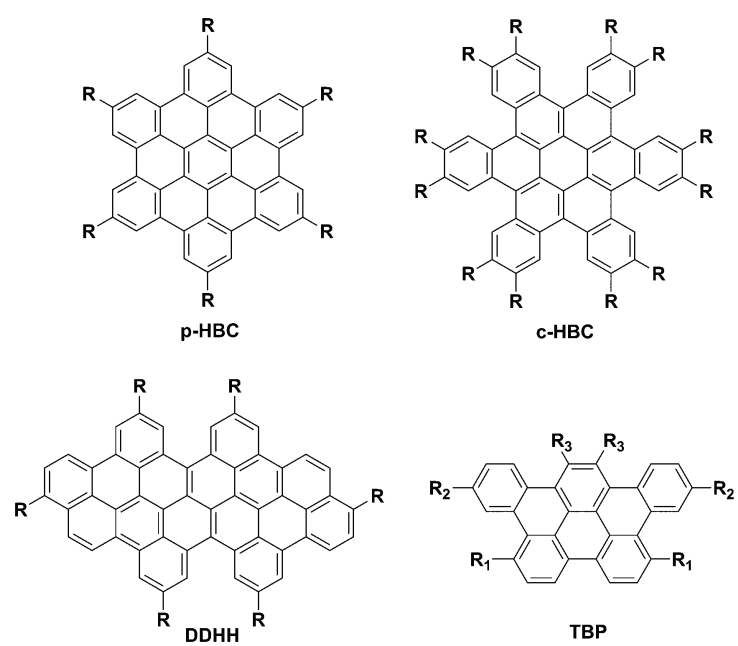

Fig. 1 Schematic representation of selected PAHs. Symmetrical planar $(\mathrm{p}-\mathrm{HBC}),{ }^{25}$ contorted $(\mathrm{c}-\mathrm{HBC}),{ }^{20}$ less symmetrical $(\mathrm{DDHH}),{ }^{17}$ and trapezoidal $(\mathrm{TBP})^{23}$ structures.

cyclodehydrogenation final step, mainly the Scholl reaction which requires a Lewis acid and an oxidant. ${ }^{21,22}$ As part of our research on PAH derivatives with tapered symmetry, we reported recently the synthesis and structural characterization of a family of the trapezoidal tribenzo[ $[g, i j, r s t]$ pentaphene (TBP) derivatives bearing various aromatic side groups either at their wide or narrow bases. ${ }^{23,24}$ Building upon this result, we aimed at synthesizing more laterally extended derivatives than TBP, 
namely dibenzo[ $f g, m n]$ phenanthro[2,1,10,9,8,7-vwxyza1b1]heptaphene (DBPH, 1) and tetrabenzo[def,lm,o,qrs] triphenyleno[2,1,12yzab]pyranthrene (TBTP, 2). The higher conjugation of compounds $\mathbf{1}$ and $\mathbf{2}$ is expected to lower their respective HOMO-LUMO energy gaps and hence improve their electron/hole charge carrier mobility. We attempted both convergent and divergent strategies to synthesise 1 and $\mathbf{2}$ by modifying and extending the conventional routes. However, lateral functionalization by Suzuki-Miyaura cross-coupling and Scholl cyclodehydrogenation reactions were the key steps to make the target molecules. Herein we report the synthesis, structural characterization, and photophysical properties of the first examples of laterally stretched graphene cross-section derivatives $\mathbf{1 a}-\mathbf{c}$ and $\mathbf{2 a - b}$.

\section{Results and discussion}

Scheme 1 summarizes our strategy for preparing the target derivatives DBPH and TBTP. We have recently reported the synthesis of compound 3 , which involves the Knoevenagel condensation reaction of 2,7-dibromophenanthrene-9,10-dione and 1,3-diphenylpropan-2-one yielding 5,10-dibromo-1,3-diphenyl$2 H$-cyclopenta[ $l]$ phenanthren-2-one. The latter undergoes a $[4+2]$ Diels-Alder cycloaddition reaction with phenyl vinyl sulfoxide affording 6,11-dibromo-1,4-diphenyltriphenylene, whose cyclodehydrogenation reaction provides 3 in good yield. ${ }^{23}$ Lateral substitution of $\mathbf{3}$ with aryl groups was then possible under optimized Suzuki-Miyaura cross-coupling reaction conditions, ${ }^{26}$ leading to the formation of TBP derivatives $4 a-c$ (Scheme 1a). Before proceeding to the next step, the diarylated TBP derivatives 4a-c underwent additional purification through a series of Soxhlet extractions by washing off the impurities successively with hexane/ pentane/petroleum ether, and diethyl ether for 4 hours each, followed by extracting the desired compounds from hot toluene over the course of 24 hours. Scholl cyclodehydrogenation reaction of TBP derivatives $\mathbf{4 a - c}$ using iron(III) chloride in nitromethane yielded the desired fully aromatized DBPH derivatives 1a-c in very good yields.

A similar strategy was employed to prepare TBTP derivatives $\mathbf{2 a - b}$ (Scheme 1b). Synthon 7 was isolated as a green solid after the Knoevenagel condensation reaction of $\mathbf{5}$ and $\mathbf{6}$. Compound 7 then underwent [4+2] Diels-Alder cycloaddition reaction with phenylvinyl sulfoxide in refluxing toluene to yield 6,11-dibromo1,4-bis(4-bromophenyl)triphenylene 8. The latter synthon was fully aromatized via the Scholl cyclodehydrogenation reaction affording 3,5,10,12-tetrabromotribenzo[fg,ij,rst]pentaphene, 9. Palladium-catalysed Suzuki-Miyaura cross-coupling reaction ${ }^{26}$ of 9 with the suitable $p$-alkyl benzene boronic acid or ester led to the isolation of tetra-substituted TBP derivatives 10a-b. Synthesis of the target TBTP derivatives $\mathbf{2} \mathbf{a}-\mathbf{b}$ was then achieved by carrying out a second Scholl cyclodehydrogenation reaction. It should be noted that like the TBP synthons their respective TBTP products were purified by a series of Soxhlet extraction processes in order to ensure high purity of the final products.

It is worth mentioning that we have attempted an easier approach that requires fewer synthetic steps to prepare $\mathbf{1}$ and $\mathbf{2}$. (a)
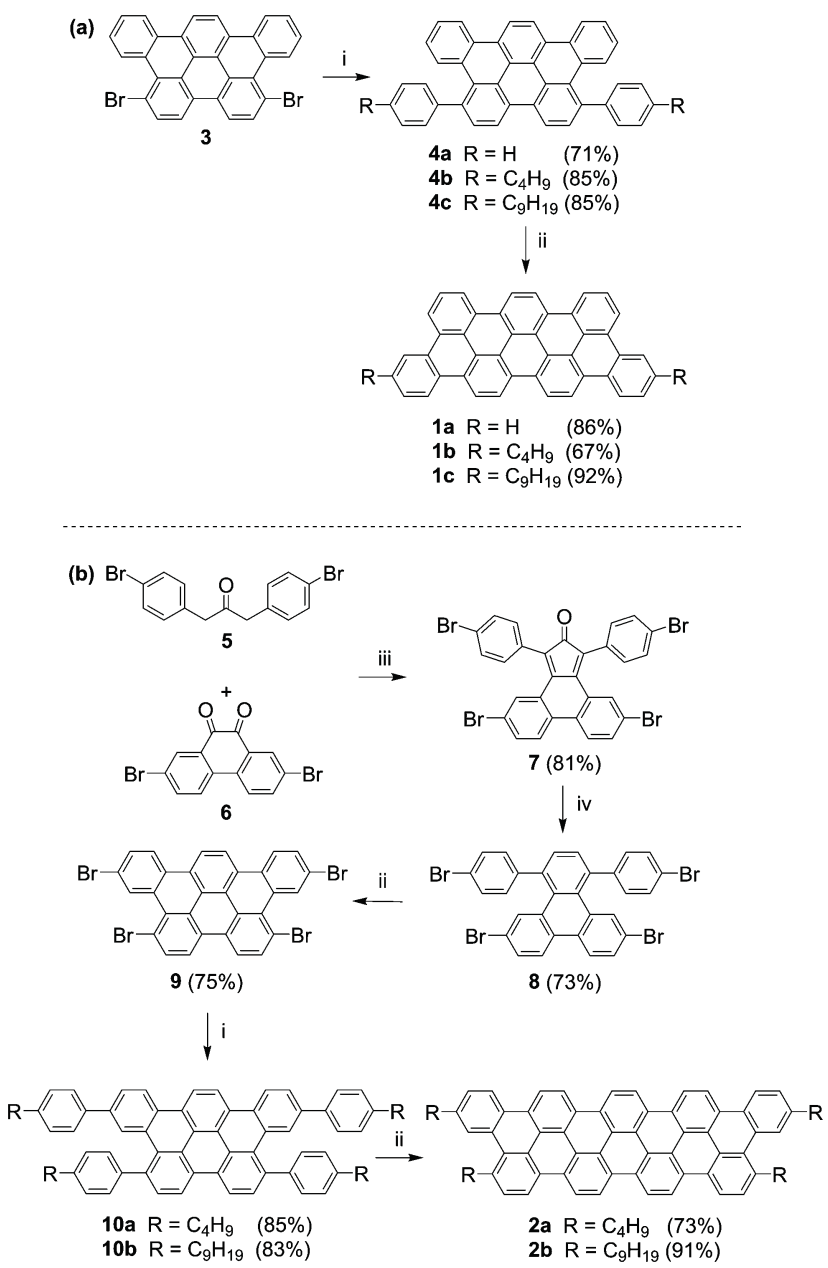

Scheme 1 Synthesis of DBPH (1) and TBTP (2) derivatives. Reagents and conditions: (i) $\left[\mathrm{Pd}_{2}(\mathrm{dba})_{3}\right], \mathrm{K}_{3} \mathrm{PO}_{4}$, Sphos, boronic acid/ester, toluene/toluenebutanol (1:1), $110{ }^{\circ} \mathrm{C}, 96 \mathrm{~h}$; (ii) $\mathrm{FeCl}_{3}, \mathrm{MeNO}_{2}, \mathrm{CH}_{2} \mathrm{Cl}_{2}, 45{ }^{\circ} \mathrm{C}$; (iii) $\mathrm{KOH}$, methanol, reflux, $4 \mathrm{~h}$; (iv) phenylvinyl sulfoxide, toluene, reflux, $24 \mathrm{~h}$.

This shorter pathway consists of reacting di- and tetrabromo1,4-diphenyltriphenylene synthons with aryl boronic acids/ esters under Suzuki-Miyaura cross coupling reaction conditions to make the corresponding di- and tetra-arylated-1,4-diphenyltriphenylene whose subsequent Scholl cyclodehydrogenation would provide DBPH and TBTP. However, all the efforts to prepare di- and tetra-arylated-1,4-diphenyltriphenylene have failed. Alternatively, we have developed a convergent synthetic route to make DBPH derivatives more conveniently by avoiding the synthesis of the less-soluble TBP intermediate 3 (Scheme 2). This synthetic strategy involves a double arylation of 6 via Suzuki-Miyaura cross-coupling reaction. The resulting compounds 11a-b underwent a Knoevenagel condensation with 1,3-diphenylpropan-2-one affording 12a-b. [4+2] Diels-Alder cycloaddition reactions of the latter synthons with phenylvinyl sulfoxide yielded tetraphenyl triphenylene derivatives $\mathbf{1 3} \mathbf{a}-\mathbf{b}$, which were subsequently aromatized to their respective DBPH derivatives $\mathbf{1 a}-\mathbf{b}$ by a single Scholl cyclodehydrogenation reaction step.

It is noteworthy that $\mathbf{1 a - b}$ and $\mathbf{2 a}$ have very low solubility in common organic solvents. Insertion of nonyl chains into DBPH 


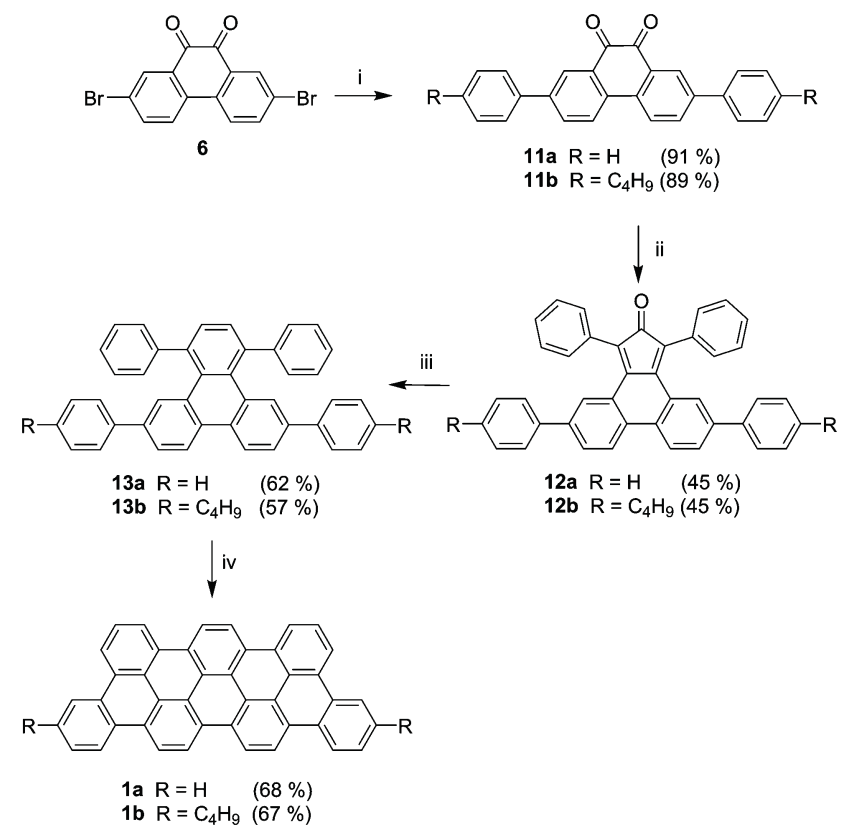

Scheme 2 Alternative route to DBPH (1) derivatives. Reagents and conditions: (i) $\left[\mathrm{Pd}_{2}(\mathrm{dba})_{3}\right], \mathrm{K}_{3} \mathrm{PO}_{4}$, Sphos, boronic acid/ester, toluene/toluene-butanol (1:1), $110{ }^{\circ} \mathrm{C}, 96 \mathrm{~h}$; (ii) 1,3-diphenylpropan-2-one, $\mathrm{KOH}$, methanol, reflux, $4 \mathrm{~h}$; (iii) phenylvinyl sulfoxide, toluene, reflux, 24 h; (iv) $\mathrm{FeCl}_{3}, \mathrm{MeNO}_{2}$, $\mathrm{CH}_{2} \mathrm{Cl}_{2}, 45^{\circ} \mathrm{C}$.

and TBTP cores (i.e. 1c and $2 \mathbf{b}$ ) only slightly improved their solubility in organic solvents, such as dichloromethane, tetrahydrofuran, and toluene. Nevertheless, even though some of the DBPH and TBTP target compounds could be analysed by ${ }^{1} \mathrm{H}-\mathrm{NMR}$ spectroscopy, it was impossible to record their ${ }^{13} \mathrm{C}$ NMR spectra. Consequently, we have employed an efficient and well-known analytical tool for the characterization of PAH materials with low solubility, and that is high-resolution matrixassisted laser desorption ionization-time of flight mass spectrometry (HR-MALDI-TOF-MS) using trans-2-[3-(4-t-butyl-phenyl)-2methyl-2-propenylidene]-malononitrile (DCTB) as the matrix. The aforementioned technique reveals the presence of compounds 1a-c and 2a-b without any noticeable impurities resulting from the starting materials or partially cyclodehydrogenated intermediates. Fig. 2 shows the isotopic patterns of 1 a and $2 \mathrm{c}$ compared to their respective calculated peaks revealing examples on the high purity of the isolated compounds (see the ESI $\dagger$ for the HR-MALDI-TOF-MS spectra of the other derivatives).

The photophysical characteristics of TBP synthons (4a-c and 10a-b) as well as the target compounds DBPH (1a-c) and TBTP $(\mathbf{2 a}-\mathbf{b})$ were investigated by means of UV-Vis absorption and emission spectroscopy using THF as solvent (Fig. 3). All the aforementioned derivatives displayed absorption spectra with a strong absorption band at $c a .300-310 \mathrm{~nm}$ in addition to broad shoulder bands ranging from $350 \mathrm{~nm}$ to $380 \mathrm{~nm}$. Synthons $4 a-c$ and 10a-b showed a strong emission band ranging between $410 \mathrm{~nm}$ and $420 \mathrm{~nm}$, which is characteristic of the TBP core. ${ }^{23,27}$ Emission spectra of 1a-c were red-shifted by 10-20 $\mathrm{nm}$ when compared to their TBP synthons, revealing fluorescence peaks at $\sim 435 \mathrm{~nm}$ in addition to shoulder peaks at $\sim 465 \mathrm{~nm}$.
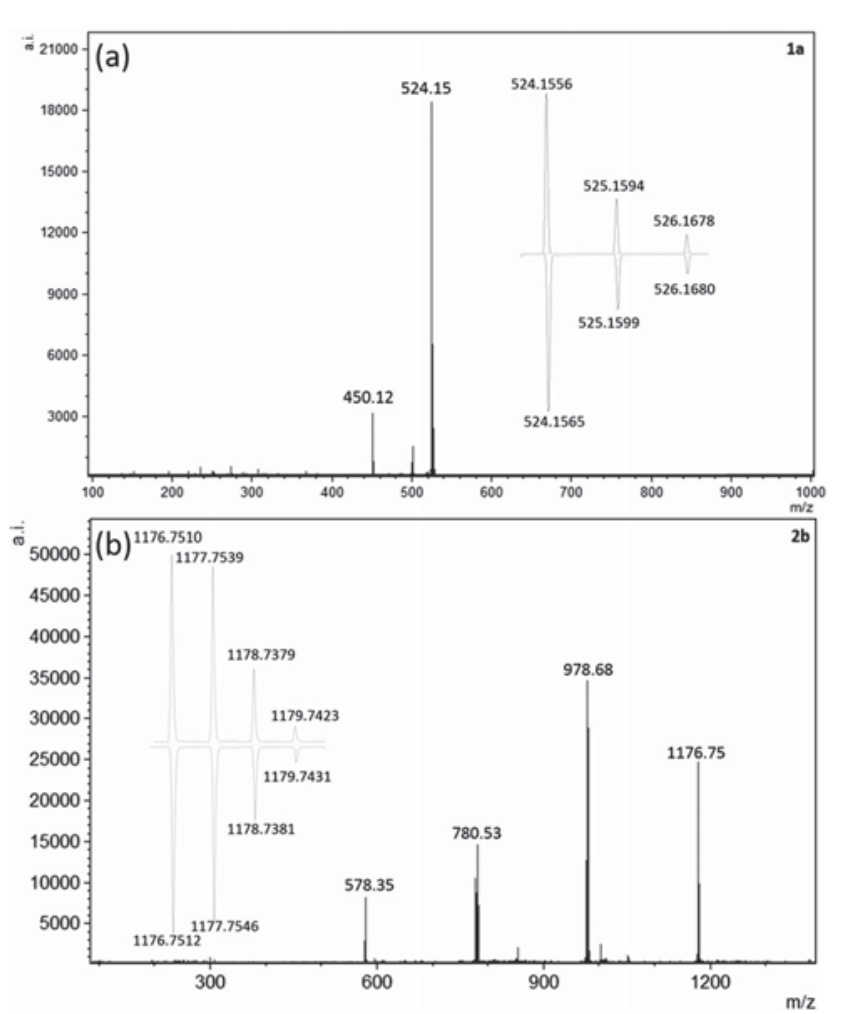

Fig. 2 (a) HR-MALDI-TOF spectrum of 1a in DCTB; inset: measured (up) and calculated (down) isotopic patterns of $\mathrm{C}_{42} \mathrm{H}_{20}{ }^{+\bullet}$ (b) HR-MALDI-TOF spectrum of $\mathbf{2 b}$ in DCTB; inset: measured (up) and calculated (down) isotopic patterns of $\mathrm{C}_{70} \mathrm{H}_{56}{ }^{+\bullet}$.

Similarly, the bands in the emission spectra of the more extended core TBTP (2a-b) were red-shifted by $\sim 30 \mathrm{~nm}$ with respect to their TBP synthons, showing an intense peak at $\sim 445 \mathrm{~nm}$ and a less intense shoulder peak at $\sim 475 \mathrm{~nm}$. The bathochromic shifts in the emission of DBPH and TBTP are expected due to the higher conjugation of their aromatic core versus the smaller aromatic core size of the TBP starting materials.

Density functional calculations of DBPH and TBTP (with $\mathrm{R}=\mathrm{H}$ or $\mathrm{CH}_{3}$ ) were carried out using B3LYP at the 6-31G* level basis set. Optimized structures of the target compounds (Table S1 in the ESI $\dagger$ ) confirm our explanation for the bathochromic shift in the emission properties when compared to their TBP synthons. It is worth noting that the optimized structures of DPBH reveal that its core retains its planar configuration even when it is doubly substituted by methyl groups. On the other hand, the TBTP core deviates from planarity and its structure becomes contorted when it is laterally substituted by four methyl groups whose steric hindrance induces a $\sim 20^{\circ}$ dihedral angle at the bay region. Table 1 summarizes the HOMO-LUMO energy gaps obtained from the $0 \rightarrow 0$ transition bands of the absorption-emission spectra (Fig. 3), and which were found to be $\sim 405$ and $400 \mathrm{~nm}$ for target compounds $\mathbf{1 a}-\mathbf{c}$ and $2 \mathbf{a}-\mathbf{b}$, respectively. The unexpectedly high HOMO-LUMO energy gaps observed for $\mathbf{2 a - b}$ could be well attributed to the deviation from planarity discussed above, which hampers the full conjugation of the aromatic core. 

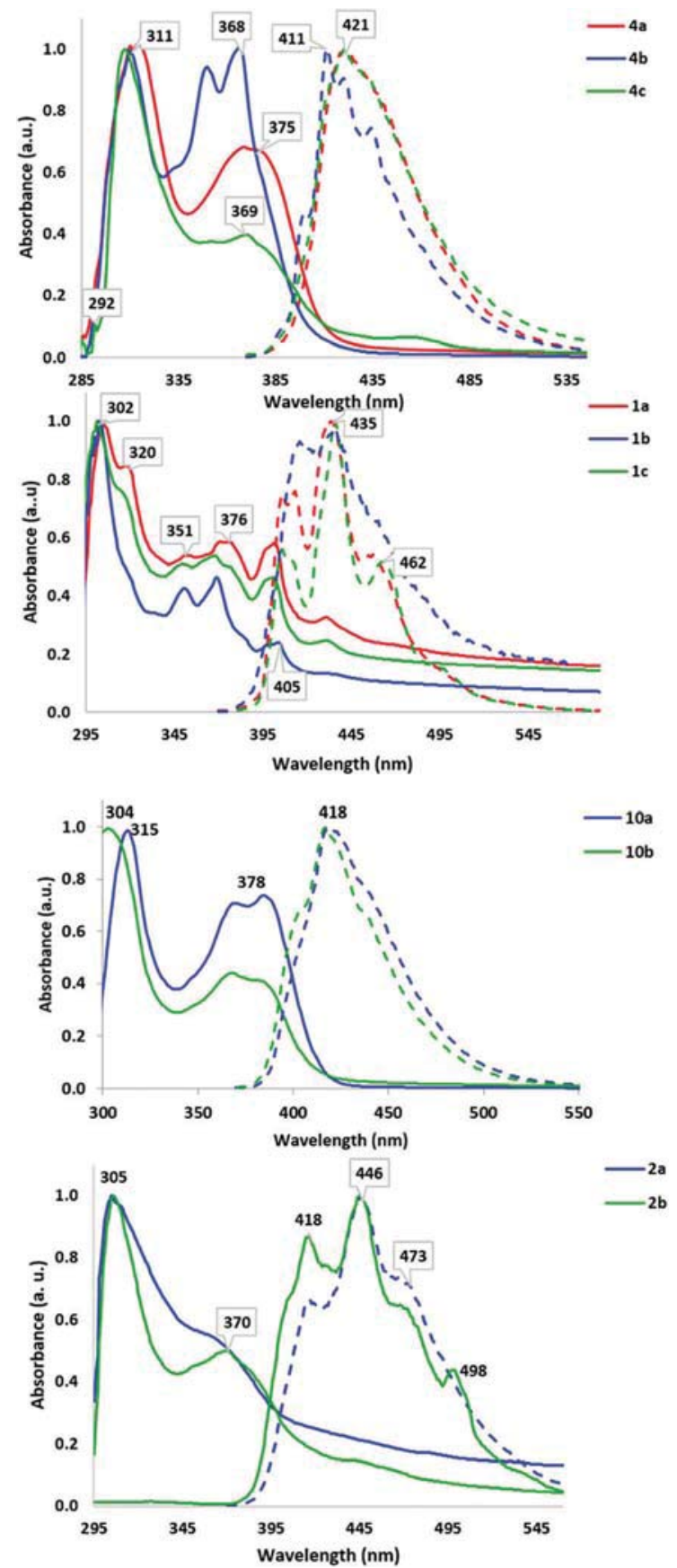

Fig. 3 Normalized absorption and emission spectra of the tribenzopentaphene derivatives $\mathbf{4 a - c}, \mathbf{1} \mathbf{a}-\mathbf{c}, \mathbf{1 0} \mathbf{a}-\mathbf{b}$, and $\mathbf{2} \mathbf{a}-\mathbf{b}$ in THF. The solid lines represent absorption spectra and the dotted lines correspond to emission spectra.

\section{Conclusions}

The versatile synthesis of a new class of laterally stretched trapezoidal PAH derivatives is shown herein, namely dibenzophenanthroheptaphene (DBPH) and tetrabenzotriphenylenopyranthrene (TBTP). The absorption and emission spectroscopic studies of these novel compounds display unique patterns and suggest in agreement with DFT calculations lower HOMO-LUMO energy gaps than the tapered tribenzopentaphene, which has a smaller aromatic core. Interestingly, the introduction of adjacent
Table 1 Observed and calculated ( $\mathrm{R}=\mathrm{H}$ or Me) HOMO-LUMO orbitals of DBPH and TBTP derivatives

\begin{tabular}{lllll}
\hline & & & \multicolumn{2}{c}{ HOMO-LUMO gap (eV) } \\
\cline { 5 - 5 } Entry & HOMO $^{a}(\mathrm{eV})$ & LUMO $^{a}(\mathrm{eV})$ & Obs. $^{b}$ & Cal. \\
\hline 1a & -5.06 & -1.85 & 3.07 & 3.21 \\
1b & $-4.98^{c}$ & $-1.79^{c}$ & 3.13 & $3.19^{c}$ \\
1c & $-4.98^{c}$ & $-1.79^{c}$ & 3.08 & $3.19^{c}$ \\
2a & $-4.78^{c}$ & $-1.94^{c}$ & 3.1 & $2.84^{c}$ \\
2b & $-4.78^{c}$ & $-1.94^{c}$ & 3.1 & $2.84^{c}$
\end{tabular}

${ }^{a}$ Calculated at the level of the B3LYP/6-31G* basis set. ${ }^{b}$ Determined from $0 \rightarrow 0$ transitions. ${ }^{c}$ With $\mathrm{R}=\mathrm{CH}_{3}$.

alkyl groups at the wide and congested bases of TBTP causes its core to deviate from planarity at the bay region leading to a contorted aromatic structure. These new DBPH and TBTP derivatives expand the scope of producing unsymmetrical tapered PAH derivatives with customizable structural modifications for applications in optical and electronic devices and use as synthons to produce graphene-related materials.

\section{Experimental section-general considerations}

All chemicals were used without further purification as purchased from Aldrich, Merck, Alfa-Aesar, and Fluorochem unless otherwise notified. All the reactions were done under a protective atmosphere using dry argon. The solvents, namely dichloromethane, ether, pentane, 1-butanol, methanol, hexane and toluene, were dried, deoxygenated, and bubbled with argon gas for 30 minutes. Millipore nitrocellulose membrane filters with $47 \mathrm{~mm}$ diameter and $0.22 \mu \mathrm{m}$ pore size were purchased from Sigma-Aldrich and HiMedia. Column chromatography was carried out using silica gel 60, (0.040-0.063 mm), from Merck or Brunschwig. Thin layer chromatography was performed on aluminum sheets coated with silica gel 60 F254 and revealed using a UV lamp. UV-Vis spectra were recorded on a VWR UV1600PC spectrophotometer. Photoluminescence spectra were recorded on an Agilent G9800 Cary Eclipse Fluorescence spectrophotometer. NMR spectra were recorded on a Bruker BioSpin $\mathrm{GmbH} 600 \mathrm{MHz}\left({ }^{1} \mathrm{H}: 600 \mathrm{MHz}\right.$, ${ }^{13} \mathrm{C}$ : $150 \mathrm{MHz}$ ) spectrometer using $\mathrm{CDCl}_{3}$ or $\mathrm{CD}_{2} \mathrm{Cl}_{2}$ as solvent and the chemical shifts $(\delta)$ are given in ppm, coupling constants $(J)$ are given in $\mathrm{Hz}$, and are all with reference to tetramethylsilane (TMS). The melting point was recorded on Electrothermal IA9200 apparatus. Mass spectra were recorded on the following spectrometers: EI spectra were recorded on an HP5988A Quadrupole spectrometer and MALDI-TOF spectra were recorded on an FT/ICR Bruker 4.7 T BioApex II spectrometer. All the MALDI spectra used DCTB as the matrix with a $337 \mathrm{~nm}$ nitrogen laser.

\section{Synthesis}

5,10-Diphenyltribenzo[fg,,$\ddot{j}$, ,rst $]$ pentaphene, 4a (method A). A Schlenk tube was charged with 5,10-dibromotribenzo$[f g, i j, r s t]$ pentaphene, $3^{23}$ (200 mg, $\left.0.37 \mathrm{mmol}\right)$, phenylboronic acid (100 mg, $0.82 \mathrm{mmol})$, Tris(dibenzylideneacetone)dipalladium (34 mg, $3.7 \times 10^{-2} \mathrm{mmol}$ ), Sphos ( $30 \mathrm{mg}, 7.4 \times 10^{-2} \mathrm{mmol}$ ), and 
$\mathrm{K}_{3} \mathrm{PO}_{4}(264 \mathrm{mg}, 0.82 \mathrm{mmol})$ in $12 \mathrm{~mL}$ of a degassed $1: 1$ mixture of toluene and 1-butanol. The reaction was refluxed under argon for 3 days. The solvent was evaporated under vacuum and the resulting black mixture was extracted with dichloromethane $(50 \mathrm{~mL} \times 3)$ from a saturated aqueous solution of $\mathrm{NaHCO}_{3}$ (75 mL). The combined organic layer was washed with $\mathrm{H}_{2} \mathrm{O}$ $(100 \mathrm{~mL} \times 3)$, concentrated, precipitated using hexane followed by Millipore filtration. Soxhlet extraction of the resulting brown precipitate was then carried out with hexane $(4 \mathrm{~h})$ and diethyl ether $(4 \mathrm{~h})$. The remaining solid was extracted with hot toluene for $24 \mathrm{~h}$ yielding $141 \mathrm{mg}$ (71\%) of the desired compound as a pale orange solid.

4a. ${ }^{1} \mathrm{H}-\mathrm{NMR}$ : (600 MHz, $\mathrm{CD}_{2} \mathrm{Cl}_{2}$ ): $\delta_{\mathrm{TMS}} 9.31-9.23$ (br., $2 \mathrm{H}$, ArH), 9.14-9.01 (4H, ArH), 8.91-8.86 (br., 2H, ArH), 8.17-7.17 (br., 16H, ArH); MALDI-HRMS (DCTB): $m / z$ (\% int): 528.1876 $\left(\mathrm{M}^{\bullet+}, 100 \%\right),\left(\mathrm{m} / \mathrm{z}\right.$ calculated for $\mathrm{C}_{42} \mathrm{H}_{24}$ 528.1878); UV/VIS: (THF, $\left.10^{-5} \mathrm{M}\right), \lambda_{\max }[\mathrm{nm}]=311,375$.

5,10-Bis(4-butylphenyl)tribenzo[fg,ij,rst $]$ pentaphene, $4 \mathrm{~b}$. This compound was prepared according to "method A", using 3 (200 mg, $0.37 \mathrm{mmol}$ ), 2-(4-butylphenyl)-4,4,5,5-tetramethyl1,3,2-dioxaborolane (389 mg, $1.49 \mathrm{mmol}$ ) Tris(dibenzylideneacetone)dipalladium (34 mg, $3.7 \times 10^{-2} \mathrm{mmol}$ ), Sphos (30 mg, $\left.7.4 \times 10^{-2} \mathrm{mmol}\right)$, and $\mathrm{K}_{3} \mathrm{PO}_{4}(318 \mathrm{mg}, 1.49 \mathrm{mmol})$ in $12 \mathrm{~mL}$ of a degassed 1:1 mixture of toluene and 1-butanol. The reaction followed by work up yielded $\mathbf{4 b}$ as an orange solid (204 mg, 85\%).

4b. ${ }^{1} \mathrm{H}-\mathrm{NMR}$ : (600 MHz, $\left.\mathrm{CD}_{2} \mathrm{Cl}_{2}\right): \delta_{\mathrm{TMS}} 9.25(2 \mathrm{H}, \mathrm{ArH}), 9.12$ (d, 2H, ArH), 9.03 (d, 2H, ArH), 8.99 (d, 2H, ArH), 8.92 (d, 2H, ArH), 8.15-8.11 (br., 2H, ArH), 8.00-7.18 (br., 10H, ArH), 1.75 (br., 8H, $\mathrm{CH}_{2}-\mathrm{CH}_{3}$ ), 1.37-1.09 (br., $4 \mathrm{H}, \mathrm{CH}_{2}-\mathrm{CH}_{3}$ ), 0.92 (t, $6 \mathrm{H}$, $\mathrm{CH}_{2}-\mathrm{CH}_{3}$ ); MALDI-HRMS (DCTB): $\mathrm{m} / \mathrm{z}$ (\% int): 640.3128 $\left(\mathrm{M}^{\bullet+}, 100 \%\right),\left(\mathrm{m} / \mathrm{z}\right.$ calculated for $\mathrm{C}_{50} \mathrm{H}_{40}$ 640.3130); UV/VIS: $\left(\mathrm{THF}, 10^{-5} \mathrm{M}\right), \lambda_{\max }[\mathrm{nm}]=310,350,368$.

5,10-Bis(4-nonylphenyl)tribenzo[ $[\boldsymbol{g}, \boldsymbol{i j}, \boldsymbol{r s t}]$ pentaphene, 4c. This compound was prepared according to "method A", using 3 (200 mg, $0.37 \mathrm{mmol}$ ), 2-(4-butylphenyl)-4,4,5,5-tetramethyl-1,3,2dioxaborolane (278 mg, $1.12 \mathrm{mmol})$, Tris(dibenzylideneacetone)dipalladium (34 mg, $\left.3.7 \times 10^{-2} \mathrm{mmol}\right)$, Sphos $(30 \mathrm{mg}, 7.4 \times$ $10^{-2} \mathrm{mmol}$ ), and $\mathrm{K}_{3} \mathrm{PO}_{4}(238 \mathrm{mg}, 1.12 \mathrm{mmol})$ in $12 \mathrm{~mL}$ of a degassed 1:1 mixture of toluene and 1-butanol. The reaction followed by work up yielded $4 \mathrm{c}$ as an orange solid (204 $\mathrm{mg}, 85 \%$ ).

4c. ${ }^{1} \mathrm{H}-\mathrm{NMR}:\left(600 \mathrm{MHz}, \mathrm{CD}_{2} \mathrm{Cl}_{2}\right): \delta_{\mathrm{TMS}} 9.16-8.80$ (br., $4 \mathrm{H}$, ArH), 8.08 (br., 1H, ArH), 7.96 (d, 4H, ArH), 7.78 (br., 2H, ArH), 7.58 (t, 1H, ArH), 7.43 (m, 4H, ArH), 7.32 (d, 4H, ArH), 7.13 (br., 2H, ArH), 2.75 (br., $4 \mathrm{H}, \mathrm{CH}_{2}-\mathrm{CH}_{3}$ ), 1.40-1.26 (br., $28 \mathrm{H}, \mathrm{CH}_{2}-\mathrm{CH}_{3}$ ), 0.91 (t, 6H, $\mathrm{CH}_{2}-\mathrm{CH}_{3}$ ); MALDI-HRMS (DCTB): $\mathrm{m} / \mathrm{z}$ (\% int): $780.4642\left(\mathrm{M}^{\bullet+}, 100 \%\right),\left(\mathrm{m} / \mathrm{z}\right.$ calculated for $\left.\mathrm{C}_{60} \mathrm{H}_{60} 780.4695\right)$; UV/VIS: (THF, $\left.10^{-5} \mathrm{M}\right), \lambda_{\max }[\mathrm{nm}]=310,369$.

Dibenzo[fg,mn]phenanthro[2,1,10,9,8,7-vwxyza1b1] heptaphene, $1 \mathrm{a}(\operatorname{method} \mathrm{B})$. To a solution of $4 \mathrm{a}(100 \mathrm{mg}, 0.19 \mathrm{mmol})$ in dichloromethane $(25 \mathrm{~mL})$ and purged with argon for $30 \mathrm{~min}$, was added a degassed solution of $\mathrm{FeCl}_{3}(0.61 \mathrm{~g}, 3.8 \mathrm{mmol}$, 20 eq.) in $\mathrm{CH}_{3} \mathrm{NO}_{2}(2.6 \mathrm{~mL})$ over $10 \mathrm{~min}$. The reaction medium was refluxed for 6 hours where the color turned from light yellow to dark-brown. After evaporation of DCM, $150 \mathrm{ml}$ of $1 \mathrm{M}$ $\mathrm{HCl}$ solution were added to the residue and the resulting green suspension was sonicated for $30 \mathrm{~min}$ and filtered using a Millipore filter. The precipitate was washed several times with water and pentane. The precipitate was sonicated for 15 minutes in diethyl ether $(5 \mathrm{~mL})$, followed by THF, re-precipitated using hexane and dried, yielding $86 \mathrm{mg}$ (86\%) of the desired compound as a dark brown powder.

1a. MALDI-HRMS (DCTB): $m / z$ (\% int): $524.155\left(\mathrm{M}^{\bullet+}, 100 \%\right)$, $\left(\mathrm{m} / z\right.$ calculated for $\left.\mathrm{C}_{42} \mathrm{H}_{20} 524.1556\right)$; UV/VIS: (THF, $\left.10^{-5} \mathrm{M}\right)$, $\lambda_{\text {max }}[\mathrm{nm}]=302,320,351,376,403$.

3,14-Dibutyldibenzo[fg,mn]phenanthro[2,1,10,9,8,7-vwxyza1b1]heptaphene, 1b. This compound was prepared according to 'method B' using $\mathbf{4 b}(60 \mathrm{mg}, 0.09 \mathrm{mmol})$ and a degassed solution of $\mathrm{FeCl}_{3}$ (303 mg, $1.8 \mathrm{mmol}, 20$ eq.) in $\mathrm{CH}_{3} \mathrm{NO}_{2}(1.2 \mathrm{~mL})$ in dichloromethane $(20 \mathrm{~mL})$. The reaction followed by work up yielded $\mathbf{1 b}$ as a dark brown solid (40 mg, 67\%).

1b. MALDI-HRMS (DCTB): $m / z$ (\% int): $636.2819\left(\mathrm{M}^{\bullet+}, 100 \%\right)$, $\left(\mathrm{m} / z\right.$ calculated for $\mathrm{C}_{50} \mathrm{H}_{36}$ 636.2817); UV/VIS: (THF, $10^{-5} \mathrm{M}$ ), $\lambda_{\text {max }}[\mathrm{nm}]=302,354,370,403$.

3,14-Dinonyldibenzo[fg,mn]phenanthro[2,1,10,9,8,7-vwxyza1b1]heptaphene, 1c. This compound was prepared according to 'method B' using 4c (100 mg, $0.128 \mathrm{mmol})$ and a degassed solution of $\mathrm{FeCl}_{3}\left(415 \mathrm{mg}, 2.56 \mathrm{mmol}, 20\right.$ eq.) in $\mathrm{CH}_{3} \mathrm{NO}_{2}(2 \mathrm{~mL})$ in dichloromethane $(20 \mathrm{~mL})$. The reaction followed by work up yielded $88 \mathrm{mg}(92 \%)$ of the desired compound as a dark brown powder.

1c. MALDI-HRMS (DCTB): ${ }^{1} \mathrm{H}-\mathrm{NMR}:\left(600 \mathrm{MHz}, \mathrm{CD}_{2} \mathrm{Cl}_{2}\right): \delta_{\mathrm{TMS}}$ 9.30 (s, 2H, ArH), 9.15-8.92 (m, 8H, ArH), 8.17 (2H, ArH), 7.83 (br. $6 \mathrm{H}, \mathrm{ArH}), 1.26$ (br., $24 \mathrm{H}$, alkyl-H), 1.15 (m, $8 \mathrm{H}, \mathrm{CH}_{3}-\mathrm{CH}_{2}$ ), 0.87 (t, $\left.6 \mathrm{H}, \mathrm{CH}_{3}-\mathrm{CH}_{2}\right) ; \mathrm{m} / \mathrm{z}$ (\% int): $776.4380\left(\mathrm{M}^{\bullet+}, 100 \%\right),(\mathrm{m} / \mathrm{z}$ calculated for $\mathrm{C}_{50} \mathrm{H}_{56}$ 776.4382); UV/VIS: (THF, $10^{-5} \mathrm{M}$ ), $\lambda_{\text {max }}[\mathrm{nm}]=302,322,350,377,405$.

5,10-Dibromo-1,3-bis(4-bromophenyl)-2H-cyclopenta[ $[$ phenanthren-2-one, 7. To a solution of 2,7-dibromophenanthrene-9,10dione, 6 (1.2 g, $3.27 \mathrm{mmol}$ ) and 1,3-bis(4-bromophenyl)propan-2one, 5 ( $3.2 \mathrm{~g}, 3.27 \mathrm{mmol}$ ) in methanol (50 mL), $\mathrm{KOH}$ (8 mg in $2 \mathrm{~mL}$ methanol) was added dropwise. The mixture was then refluxed for $6 \mathrm{~h}$ and cooled to room temperature. The green precipitate was filtered using a Millipore filter and washed with methanol (10 mL), yielding $1.8 \mathrm{~g}(81 \%)$ of the desired compound 7 as a green solid.

7. ${ }^{1} \mathrm{H}-\mathrm{NMR}:\left(600 \mathrm{MHz}, \mathrm{CD}_{2} \mathrm{Cl}_{2}\right): \delta_{\mathrm{TMS}} 7.83(\mathrm{~d}, 2 \mathrm{H}, \mathrm{ArH})$, 7.67-7.61 (m, 4H, ArH), 7.57 (d, 2H, ArH), 7.46 (m, 2H, ArH), 7.29-7.35 (br., $4 \mathrm{H}, \mathrm{ArH}) ;{ }^{13} \mathrm{C}$ NMR (150 MHz, $\left.\mathrm{CDCl}_{3}\right): \delta_{\mathrm{TMS}}$ $196.20(\mathrm{C}=\mathrm{O}), 139.13,135.78,134.68,133.57,132.36,131.76$, 130.38, 129.48, 129.33, 125.79, 124.86, 122.68; m.p. > $300{ }^{\circ} \mathrm{C}$ (decomp.); EI-MS = m/z (\% int): $697.7732\left([\mathrm{M}-\mathrm{H}]^{++}, 100(\mathrm{~m} / z\right.$ calcd for $\left.\mathrm{C}_{29} \mathrm{H}_{14} \mathrm{Br}_{4} \mathrm{O}: 697.7737\right)$ ).

6,11-Dibromo-1,4-bis(4-bromophenyl)triphenylene, 8. 5,10Dibromo-1,3-bis(4-bromophenyl)-2H-cyclopenta[l]phenanthren2-one, 7 (0.65 g, $0.93 \mathrm{mmol})$ and phenylvinylsulfoxide $(152 \mathrm{mg}$, $1 \mathrm{mmol}, 0.13 \mathrm{~mL}$ ) were refluxed under argon in dry toluene $(15 \mathrm{~mL}$ ) for $24 \mathrm{~h}$. After cooling to room temperature, the solvent was evaporated and the crude product was concentrated, precipitated using hexane followed by Millipore filtration, affording the desired product as a yellow solid (473 mg, 73\%).

8. ${ }^{1} \mathrm{H}-\mathrm{NMR}:\left(600 \mathrm{MHz}, \mathrm{CD}_{2} \mathrm{Cl}_{2}\right.$ ): $\delta_{\mathrm{TMS}} 8.62$ (q., $\left.1 \mathrm{H}, \mathrm{ArH}\right), 8.27$ (br., 1H, ArH), 7.88-7.61 (br., 4H, ArH), 7.60-7.43 (br., 6H, ArH), 
7.35 (m, 1H, ArH), 7.31 (d, 1H, ArH), 7.13-6.84 (br., 2H, ArH); ${ }^{13} \mathrm{C}$ NMR $\left(150 \mathrm{MHz}, \mathrm{CDCl}_{3}\right): \delta_{\mathrm{TMS}} 142.94,136.92,132.81$, 132.63, 132.50, 131.92, 131.59, 130.81, 130.14, 129.81, 129.09, 126.48, 124.90; m.p. $>300{ }^{\circ} \mathrm{C}$ (decomp.); EI-MS = m/z (\% int): $695.7980\left([\mathrm{M}-\mathrm{H}]^{\circ+}, 100\left(\mathrm{~m} / z\right.\right.$ calcd for $\mathrm{C}_{30} \mathrm{H}_{16} \mathrm{Br}_{4}$ : 695.7945)).

$\mathbf{3 , 5 , 1 0 , 1 2 - T e t r a b r o m o t r i b e n z o}[\boldsymbol{f g}, \boldsymbol{i j}, \boldsymbol{r s t}]$ pentaphene, 9. This compound was prepared according to 'method B' using 6,11dibromo-1,4-bis(4-bromophenyl)triphenylene, 8 ( $400 \mathrm{mg}, 0.57 \mathrm{mmol}$ ) and a degassed solution of $\mathrm{FeCl}_{3}(1.86 \mathrm{~g}, 11.49 \mathrm{mmol}, 20$ eq. $)$ in $\mathrm{CH}_{3} \mathrm{NO}_{2}(8.4 \mathrm{~mL})$ in dichloromethane $(10 \mathrm{~mL})$. The reaction followed by work up yielded $297 \mathrm{mg}$ (75\%) of the desired compound as a dark brown powder.

9. ${ }^{1} \mathrm{H}-\mathrm{NMR}:\left(600 \mathrm{MHz}, \mathrm{CD}_{2} \mathrm{Cl}_{2}\right)$ : $\delta_{\mathrm{TMS}} 8.70$ (d, 2H, ArH), 7.94 (dd., 2H, ArH), 7.80 (d, 2H, ArH), 7.58 (s, 6H, ArH); MALDI-HRMS (DCTB): $m / z$ (\% int): $691.7749\left(\mathrm{M}^{\bullet+}, 100 \%\right)$, ( $m / z$ calculated for $\mathrm{C}_{30} \mathrm{H}_{12} \mathrm{Br}_{4}$ 691.7632); UV/VIS: (THF, $10^{-5} \mathrm{M}$ ), $\lambda_{\text {max }}[\mathrm{nm}]=301,313,366,389$.

3,5,10,12-Tetrakis(4-butylphenyl)tribenzo[fg, $\boldsymbol{j}$, ,rst $]$ pentaphene, 10a. This compound was prepared according to "method A", using 3,5,10,12-tetrabromotribenzo[fg, $, j, r s t]$ pentaphene, 9 (200 mg, $0.29 \mathrm{mmol}$ ), (4-butylphenyl)boronic acid (185 mg, $1.04 \mathrm{mmol}$ ), Tris(dibenzylideneacetone)dipalladium (26 mg, $2.8 \times 10^{-2} \mathrm{mmol}$ ), Sphos ( $\left.23 \mathrm{mg}, 5.7 \times 10^{-2} \mathrm{mmol}\right)$, and $\mathrm{K}_{3} \mathrm{PO}_{4}(220 \mathrm{mg}, 1.04 \mathrm{mmol})$ in $12 \mathrm{~mL}$ of a degassed 1:1 mixture of toluene and 1-butanol. The reaction followed by work up yielded 10a as an orange solid (204 mg, 85\%).

10a. ${ }^{1} \mathrm{H}-\mathrm{NMR}:\left(600 \mathrm{MHz}, \mathrm{CD}_{2} \mathrm{Cl}_{2}\right): \delta_{\mathrm{TMS}} 9.86$ (br., $\left.4 \mathrm{H}, \mathrm{ArH}\right)$, 7.94 (br., 2H, ArH), 7.75 (d, 4H, ArH), 7.53-7.43 (br., 8H, ArH), 7.17-7.08 (br., 8H, ArH), 7.48-7.36 (br., 8H, ArH), 4.52-1.6 (br., $\left.24 \mathrm{H}, \mathrm{CH}_{2}-\mathrm{CH}_{3}\right), 1.16\left(\mathrm{t}, 6 \mathrm{H}, \mathrm{CH}_{2}-\mathrm{CH}_{3}\right), 0.86\left(\mathrm{t}, 6 \mathrm{H}, \mathrm{CH}_{2}-\mathrm{CH}_{3}\right)$; MALDI-HRMS (DCTB): $m / z$ (\% int): $904.5007\left(\mathrm{M}^{\bullet+}, 100 \%\right)$, ( $\mathrm{m} / \mathrm{z}$ calculated for $\mathrm{C}_{70} \mathrm{H}_{64}$ 904.5008); UV/VIS: (THF, $10^{-5} \mathbf{M}$ ), $\lambda_{\max }[\mathrm{nm}]=315,370,389$.

3,5,10,12-Tetrakis(4-nonylphenyl)tribenzo[ $f g, i j, r s t]$ pentaphene, 10b. This compound was prepared according to "method A", using 3,5,10,12-tetrabromotribenzo[fg,ij,rst]pentaphene, 9 (200 mg, $0.28 \mathrm{mmol}$ ), (4-nonylphenyl)boronic acid (342 mg, $1.38 \mathrm{mmol}$ ), Tris(dibenzylideneacetone)dipalladium ( $26 \mathrm{mg}, 2.8 \times 10^{-2} \mathrm{mmol}$ ), Sphos ( $\left.23 \mathrm{mg}, 5.7 \times 10^{-2} \mathrm{mmol}\right)$, and $\mathrm{K}_{3} \mathrm{PO}_{4}(220 \mathrm{mg}, 1.04 \mathrm{mmol})$ in $12 \mathrm{~mL}$ of a degassed 1:1 mixture of toluene and 1-butanol. The reaction followed by work up yielded $\mathbf{9 b}$ as an orange solid (284 mg, 83\%).

10b. ${ }^{1} \mathrm{H}-\mathrm{NMR}:\left(600 \mathrm{MHz}, \mathrm{CD}_{2} \mathrm{Cl}_{2}\right): \delta_{\mathrm{TMS}} 9.08-8.63$ (br., $4 \mathrm{H}$, ArH), 7.94 (br., 2H, ArH), 7.80-7.72 (br., 6H, ArH), 7.47-7.38 (br., 10H, ArH), 7.14 (br., 6H, ArH), 2.65-2.53 (br., 6H, $\mathrm{CH}_{2}-\mathrm{CH}_{3}$ ), 1.51-1.18 (br., $64 \mathrm{H}, \mathrm{CH}_{2}-\mathrm{CH}_{3}$ ), 0.79 (br., $6 \mathrm{H}$, $\mathrm{CH}_{2}-\mathrm{CH}_{3}$ ); MALDI-HRMS (DCTB): $m / z$ (\% int): $1184.8129\left(\mathrm{M}^{\bullet+}\right.$, $100 \%),\left(\mathrm{m} / \mathrm{z}\right.$ calculated for $\mathrm{C}_{90} \mathrm{H}_{104}$ 1184.8138); UV/VIS: (THF, $\left.10^{-5} \mathrm{M}\right), \lambda_{\max }[\mathrm{nm}]=304,370,388$.

3,5,14,16-Tetrabutyltetrabenzo[def,lm,o,qrs] triphenyleno[2,1,12yzab]pyranthrene, 2a. This compound was prepared according to 'method B' using 3,5,10,12-tetrakis(4-butylphenyl)tribenzo[ $f g, \ddot{j}$, rst]pentaphene, $10 \mathrm{a}(100 \mathrm{mg}, 0.11 \mathrm{mmol})$ and a degassed solution of $\mathrm{FeCl}_{3}\left(0.71 \mathrm{~g}, 4.4 \mathrm{mmol}, 40 \mathrm{eq}\right.$.) in $\mathrm{CH}_{3} \mathrm{NO}_{2}(6.5 \mathrm{~mL})$ in dichloromethane $(15 \mathrm{~mL})$. The reaction followed by work up yielded $73 \mathrm{mg}(73 \%)$ of the desired compound as a dark brown powder. 2a. MALDI-HRMS (DCTB): $m / z$ (\% int): $896.4378\left(\mathrm{M}^{\bullet+}, 100 \%\right)$, $\left(\mathrm{m} / \mathrm{z}\right.$ calculated for $\mathrm{C}_{70} \mathrm{H}_{56}$ 896.4382); UV/VIS: (THF, $10^{-5} \mathrm{M}$ ), $\lambda_{\text {max }}[\mathrm{nm}]=305,370$.

3,5,14,16-Tetranonyltetrabenzo[def,lm,o,qrs] triphenyleno[2,1,12yzab]pyranthrene, $\mathbf{2 b}$. This compound was prepared according to 'method B' using 3,5,10,12-tetrakis(4-butylphenyl)tribenzo[ $f g, i j, r s t]$ pentaphene, 10b (100 mg, $0.08 \mathrm{mmol})$ and a degassed solution of $\mathrm{FeCl}_{3}$ (0.54 g, $3.3 \mathrm{mmol}, 40$ eq.) in $\mathrm{CH}_{3} \mathrm{NO}_{2}(4 \mathrm{~mL})$ in dichloromethane $(15 \mathrm{~mL})$. The reaction followed by work up yielded $92 \mathrm{mg}$ (93\%) of the desired compound as a dark brown powder.

2b. ${ }^{1} \mathrm{H}-\mathrm{NMR}$ : $\left(600 \mathrm{MHz}, \mathrm{CD}_{2} \mathrm{Cl}_{2}\right): \delta_{\mathrm{TMS}} 9.31$ (br., $\left.1 \mathrm{H}, \mathrm{ArH}\right)$, 9.15(br., 2H, ArH), 9.05 (d, 2H, ArH), 8.93 (br., 1H, ArH), 8.17-7.24 (br., $14 \mathrm{H}, \mathrm{ArH}$ ), 2.62 (br., $4 \mathrm{H}, \mathrm{CH}_{2}-\mathrm{CH}_{3}$ ), 1.27-1.15 (br., $\left.66 \mathrm{H}, \mathrm{CH}_{2}-\mathrm{CH}_{3}\right), 0.87\left(\mathrm{t}, 6 \mathrm{H}, \mathrm{CH}_{2}-\mathrm{CH}_{3}\right.$ ); MALDI-HRMS (DCTB): $m / z$ (\% int): $1176.7510\left(\mathrm{M}^{\bullet^{+}}, 100 \%\right),(\mathrm{m} / \mathrm{z}$ calculated for $\mathrm{C}_{90} \mathrm{H}_{96}$ 1176.7512); UV/VIS: (THF, $10^{-5} \mathrm{M}$ ), $\lambda_{\max }[\mathrm{nm}]=305,370$.

2,7-Diphenylphenanthrene-9,10-dione, 11a. This compound was prepared according to "method A", using 2,7-dibromophenanthrene-9,10-dione, 6 (500 mg, $1.37 \mathrm{mmol}$ ), phenylboronic acid (333 mg, $2.73 \mathrm{mmol}$ ), Tris(dibenzylideneacetone)dipalladium (12 mg, $1.3 \times 10^{-2} \mathrm{mmol}$ ), Sphos (11 mg, $\left.2.7 \times 10^{-2} \mathrm{mmol}\right)$, and $\mathrm{K}_{3} \mathrm{PO}_{4}(579 \mathrm{mg}, 2.73 \mathrm{mmol})$ in $10 \mathrm{~mL}$ of degassed toluene. The reaction was carried out for 4 hours followed by work up yielded 11a as an orange solid (453 $\mathrm{mg}, 91 \%)$.

11a. ${ }^{1} \mathrm{H}-\mathrm{NMR}:\left(600 \mathrm{MHz}, \mathrm{CD}_{2} \mathrm{Cl}_{2}\right): \delta_{\mathrm{TMS}} 8.47(\mathrm{~d}, 2 \mathrm{H}, \mathrm{ArH})$, 8.21 (d, 2H, ArH), 8.07-8.05 (dd, 2H, ArH), 7.78 (dd, 4H, ArH), 7.56 (t, 4H, ArH), 7.48 (t, 2H, ArH); ${ }^{13} \mathrm{C} \mathrm{NMR}\left(150 \mathrm{MHz}, \mathrm{CD}_{2} \mathrm{Cl}_{2}\right)$ : $\delta_{\text {TMS }} 180.53(\mathrm{C}=\mathrm{O}), 142.41,139.18,138.67,134.47,133.52$, $129.30,128.87,127.01,125.89,124.88$, m.p. $216{ }^{\circ} \mathrm{C}$; EI-MS = $\mathrm{m} / \mathrm{z}$ (\% int): $360.1145\left(\mathrm{M}^{\bullet+}, 100 \%\right),\left([\mathrm{M}+\mathrm{H}]^{\bullet+}, 100(\mathrm{~m} / \mathrm{z}\right.$ calcd for $\left.\mathrm{C}_{26} \mathrm{H}_{16} \mathrm{O}_{2}^{+} 360.1150\right)$ ).

1,3,5,10-Tetraphenyl-2H-cyclopenta[ $l]$ phenanthren-2-one, $12 \mathrm{a}$. To a solution of 2,7-diphenylphenanthrene-9,10-dione, 11a (150 mg, $0.416 \mathrm{mmol}$ ) and 1,3-diphenylpropan-2-one (87 mg, $0.416 \mathrm{mmol})$ in methanol $(20 \mathrm{~mL}) \mathrm{KOH}(2 \mathrm{mg}$ in $1 \mathrm{~mL}$ methanol $)$ was added dropwise. The mixture was then refluxed for $2 \mathrm{~h}$ and cooled to room temperature. The green precipitate was filtered using a Millipore filter and washed with methanol $(10 \mathrm{~mL})$ yielded $100 \mathrm{mg}(45 \%)$ of the desired compound 12a as a green solid.

12a. ${ }^{1} \mathrm{H}-\mathrm{NMR}$ : $\left(600 \mathrm{MHz}, \mathrm{CD}_{2} \mathrm{Cl}_{2}\right): \delta_{\mathrm{TMS}} 9.00$ (q, $\left.1 \mathrm{H}, \mathrm{ArH}\right)$, 8.28 (br., 1H, ArH), 7.55 (d, 4H, ArH), 8.08-7.88 (br., 4H, ArH), 7.70-7.30 (br., 18H, ArH), 7.00 (s, 2H, ArH); ${ }^{13} \mathrm{C}$ NMR (150 MHz, $\left.\mathrm{CDCl}_{3}\right): \delta_{\mathrm{TMS}} 198.37(\mathrm{C}=\mathrm{O}), 151.66,143.31,140.33,137.84$, 135.92, 134.09, 130.34, 129.69, 129.05, 128.70, 128.40, 127.88, 127.49, 125.67, 125.40, 123.78; m.p. $166^{\circ} \mathrm{C}$; EI-MS = m/z (\% int): $534.197\left([\mathrm{M}-\mathrm{H}]^{\bullet+}, 100\left(\mathrm{~m} / z\right.\right.$ calcd for $\left.\left.\mathrm{C}_{41} \mathrm{H}_{26} \mathrm{O}: 534.1984\right)\right)$.

1,4,6,11-Tetraphenyltriphenylene, 13a. 1,3,5,10-tetraphenyl$2 H$-cyclopenta[l]phenanthren-2-one, 12a $(160 \mathrm{mg}, 0.299 \mathrm{mmol})$ and phenylvinylsulfoxide $(59 \mathrm{mg}, 0.389 \mathrm{mmol}, 0.051 \mathrm{~mL}$ ) were refluxed under argon in dry toluene $(10 \mathrm{~mL})$ for $24 \mathrm{~h}$. After cooling to room temperature, the solvent was evaporated and the crude product was concentrated, and precipitated using hexane followed by Millipore filtration, affording the desired product as a pale yellow solid (100 $\mathrm{mg}, 62 \%)$.

13a. ${ }^{1} \mathrm{H}-\mathrm{NMR}:\left(600 \mathrm{MHz}, \mathrm{CDCl}_{3}\right): \delta_{\mathrm{TMS}} 7.22(\mathrm{~d}, 2 \mathrm{H}, \mathrm{ArH})$, 7.79 (d, 2H, ArH), 7.45 (dd, 2H, ArH), 7.24-7.17 (m, 10H, ArH), 
6.99 (m, 6H, ArH), 6.75 (dd, 4H, ArH); ${ }^{13} \mathrm{C}$ NMR $(150 \mathrm{MHz}$, $\left.\mathrm{CDCl}_{3}\right): \delta_{\mathrm{TMS}} 145.48,140.73,139.50,137.78,131.53,130.58$, $130.30,129.95,129.63,129.38,129.32,128.71,127.30,127.20$, 127.06, 125.57, 123.84; m.p. $217{ }^{\circ} \mathrm{C}$; EI-MS = $m / z$ (\% int): 532.2185 $\left([\mathrm{M}+\mathrm{H}]^{\bullet+}, 100\left(\mathrm{~m} / z\right.\right.$ calcd for $\left.\left.\mathrm{C}_{42} \mathrm{H}_{28}: 532.2191\right)\right)$.

Dibenzo[fg,mn]phenanthro[2,1,10,9,8,7-vwxyza1b1]heptaphene, 1a. This compound was prepared according to 'method B' using 1,4,6,11-tetraphenyltriphenylene 13a (70 $\mathrm{mg}, 0.13 \mathrm{mmol})$ and a degassed solution of $\mathrm{FeCl}_{3}\left(0.84 \mathrm{~g}, 5.2 \mathrm{mmol}, 40\right.$ eq.) in $\mathrm{CH}_{3} \mathrm{NO}_{2}$ $(6.2 \mathrm{~mL})$ in dichloromethane $(15 \mathrm{~mL})$. The reaction followed by work up yielded $55 \mathrm{mg}(68 \%)$ of the desired compound as a dark brown powder.

2,7-Bis(4-butylphenyl)phenanthrene-9,10-dione, 11b. This compound was prepared according to "method A", using 2,7-dibromophenanthrene-9,10-dione, 6 (500 mg, $1.37 \mathrm{mmol}$ ), (4-butylphenyl)boronic acid (535 mg, $3.0 \mathrm{mmol}$ ), Tris(dibenzylideneacetone)dipalladium (12 mg, $1.3 \times 10^{-2} \mathrm{mmol}$ ), Sphos (11 mg, $\left.2.7 \times 10^{-2} \mathrm{mmol}\right)$, and $\mathrm{K}_{3} \mathrm{PO}_{4}(637 \mathrm{mg}, 3.0 \mathrm{mmol})$ in $10 \mathrm{~mL}$ of degassed toluene. The reaction was carried out for 4 hours followed by work up, yielding 11b as an orange solid (577 mg, 89\%).

11b. ${ }^{1} \mathrm{H}-\mathrm{NMR}:\left(600 \mathrm{MHz}, \mathrm{CD}_{2} \mathrm{Cl}_{2}\right.$ ): $\delta_{\mathrm{TMS}} 8.43(\mathrm{~s}, 2 \mathrm{H}, \mathrm{ArH})$, 8.17 (d, 2H, ArH), 8.04 (dd, 2H, ArH), 7.69 (d, 4H, ArH), 7.38 (d, $4 \mathrm{H}, \mathrm{ArH}$ ), 4.84 (t, $4 \mathrm{H}, \mathrm{CH}_{2}-\mathrm{CH}_{3}$ ), 1.69 (quin., $4 \mathrm{H}, \mathrm{CH}_{2}-\mathrm{CH}_{3}$ ), $1.45\left(\mathrm{~m}, 4 \mathrm{H}, \mathrm{CH}_{2}-\mathrm{CH}_{3}\right), 1.00\left(\mathrm{t}, 6 \mathrm{H}, \mathrm{CH}_{2}-\mathrm{CH}_{3}\right) ;{ }^{13} \mathrm{C} \mathrm{NMR}$ $\left(150 \mathrm{MHz}, \mathrm{CD}_{2} \mathrm{Cl}_{2}\right): \delta_{\mathrm{TMS}} 180.68(\mathrm{C}=\mathrm{O}), 143.72,142.28$, $135.99,134.45,134.21,131.33,129.35,128.64,126.83$, 124.74, 35.55, 33.76, 22.54, 14.16; m.p. $141{ }^{\circ} \mathrm{C} ; \mathrm{EI}-\mathrm{MS}=\mathrm{m} / \mathrm{z}$ (\% int): $472.2396\left([\mathrm{M}+\mathrm{H}]^{\bullet+}, 100\left(\mathrm{~m} / z\right.\right.$ calcd for $\mathrm{C}_{34} \mathrm{H}_{32} \mathrm{O}_{2}$ 472.2402)).

5,10-Bis(4-butylphenyl)-1,3-diphenyl-2H-cyclopenta[l]phenanthren-2-one, $\mathbf{1 2 b}$. To a solution of 2,7-bis(4-butylphenyl)phenanthrene-9,10-dione, 11b (200 mg, $0.42 \mathrm{mmol}$ ) and 1,3-diphenylpropan-2-one ( $89 \mathrm{mg}, 0.42 \mathrm{mmol})$ in methanol $(20 \mathrm{~mL}), \mathrm{KOH}$ ( $2 \mathrm{mg}$ in $1 \mathrm{~mL}$ methanol) was added dropwise. The mixture was then refluxed for $2 \mathrm{~h}$ and cooled to room temperature. The green precipitate was filtered using a Millipore filter and washed with methanol $(10 \mathrm{~mL})$, yielding $125 \mathrm{mg}(45 \%)$ of the desired compound $\mathbf{1 2 b}$ as a green solid.

12b. ${ }^{1} \mathrm{H}-\mathrm{NMR}$ : (600 MHz, $\mathrm{CD}_{2} \mathrm{Cl}_{2}$ ): $\delta_{\mathrm{TMS}} 7.95-7.89$ (br., $2 \mathrm{H}$, ArH), 7.79 (dd, 2H, ArH), 7.64-7.45 (br., 6H, ArH), 7.40 (d, 1H, ArH), 7.36 (d, 1H, ArH), 7.31 (t, 2H, ArH), 7.22 (d, 2H, ArH), 7.15 (br., 6H, ArH), 2.68-2.60 (t, $4 \mathrm{H}, \mathrm{CH}_{2}-\mathrm{CH}_{3}$ ), 1.62 (quin., $4 \mathrm{H}$, $\left.\mathrm{CH}_{2}-\mathrm{CH}_{3}\right), 1.37\left(\mathrm{~m}, 4 \mathrm{H}, \mathrm{CH}_{2}-\mathrm{CH}_{3}\right), 0.96\left(\mathrm{t}, 6 \mathrm{H}, \mathrm{CH}_{2}-\mathrm{CH}_{3}\right) ;{ }^{13} \mathrm{C}$ NMR $\left(150 \mathrm{MHz}, \mathrm{CD}_{2} \mathrm{Cl}_{2}\right): \delta_{\text {TMS }} 201.06(\mathrm{C}=\mathrm{O}), 148.82,143.55$, 140.59, 136.69, 133.54, 130.55, 129.78, 129.57, 129.37, 129.20, $128.95,128.73,127.82,127.40,126.48,125.45,35.76,34.15$, 22.97, 14.27; m.p. $257{ }^{\circ} \mathrm{C}$ EI-MS $=m / z$ (\% int): 646.3230 $\left([\mathrm{M}-\mathrm{H}]^{\bullet+}, 100\left(\mathrm{~m} / \mathrm{z}\right.\right.$ calcd for $\left.\left.\mathrm{C}_{49} \mathrm{H}_{42} \mathrm{O}: 646.3236\right)\right)$.

6,11-Bis(4-butylphenyl)-1,4-diphenyltriphenylene, 13b. 5,10Bis(4-butylphenyl)-1,3-diphenyl-2 $H$-cyclopenta[l]phenanthren-2one, 12b (175 mg, $0.27 \mathrm{mmol}$ ) and phenylvinylsulfoxide (53 mg, $0.35 \mathrm{mmol}, 0.046 \mathrm{~mL}$ ) were refluxed under argon in dry toluene $(10 \mathrm{~mL})$ for $24 \mathrm{~h}$. After cooling to room temperature, the solvent was evaporated and the crude product was concentrated, and precipitated using hexane followed by Millipore filtration, affording the desired product as a pale yellow solid (100 mg, 57\%). 13b. ${ }^{1} \mathrm{H}-\mathrm{NMR}:\left(600 \mathrm{MHz}, \mathrm{CDCl}_{3}\right): \delta_{\mathrm{TMS}} 7.99(\mathrm{dd}, 2 \mathrm{H}, \mathrm{ArH})$, 7.81 (d, 2H, ArH), 7.39 (br., 6H, ArH), 7.37-7.32 (br., 6H, ArH), 7.27-7.25 (m, 6H, ArH), 7.22 (d, 1H, ArH), 7.13, $1.42(\mathrm{~m}, 12 \mathrm{H}$, $\left.\mathrm{CH}_{2}-\mathrm{CH}_{3}\right), 0.98\left(\mathrm{t}, 6 \mathrm{H}, \mathrm{CH}_{2}-\mathrm{CH}_{3}\right) ;{ }^{13} \mathrm{C} \mathrm{NMR}\left(150 \mathrm{MHz}, \mathrm{CDCl}_{3}\right)$ : $\delta_{\mathrm{TMS}} 142.63,139.53,137.82,137.63,136.21,130.12,129.21$, 129.13, 128.98, 128.94, 128.53, 127.67, 127.50, 127.15, 126.19, $124.52,124.01,33.75,29.85,22.55,14.11 ; \mathrm{EI}-\mathrm{MS}=m / z$ (\% int): $644.3441\left([\mathrm{M}-\mathrm{H}]^{\bullet+}, 100\left(\mathrm{~m} / z\right.\right.$ calcd for $\left.\left.\mathrm{C}_{50} \mathrm{H}_{44}: 644.3443\right)\right)$.

3,14-Dibutyldibenzo[fg,mn]phenanthro[2,1,10,9,8,7-vwxyza1b1]heptaphene, 1b. This compound was prepared according to 'method B' using 6,11-bis(4-butylphenyl)-1,4-diphenyltriphenylene $13 \mathbf{b}(70 \mathrm{mg}, 0.13 \mathrm{mmol})$ with a degassed solution of $\mathrm{FeCl}_{3}(0.85 \mathrm{~g}$, $5.2 \mathrm{mmol}, 40$ eq.) in $\mathrm{CH}_{3} \mathrm{NO}_{2}(6.2 \mathrm{~mL})$ in dichloromethane $(15 \mathrm{~mL})$. The reaction followed by work up yielded $55 \mathrm{mg}$ (67\%) of the desired compound as a dark brown powder.

\section{Acknowledgements}

The project was partially supported by the Kuwait Foundation for the Advancement of Sciences (KFAS) under project code: 2013-1506-01. BA, FS and SM acknowledge the general facilities projects GS01/03, GS03/01, and GS03/08 at Kuwait University.

\section{Notes and references}

1 C. Wang, H. Dong, W. Hu, Y. Liu and D. Zhu, Chem. Rev., 2012, 112, 2208-2267.

2 Z. Sun, Q. Ye, C. Chi and J. Wu, Chem. Soc. Rev., 2012, 41, 7857-7889.

3 X. Feng, V. Marcon, W. Pisula, M. Hansen, J. Kirkpatrick, F. Grozema, D. Andrienko, K. Kremer and K. Müllen, Nat. Mater., 2009, 8, 421-426.

4 T. Hara, K. Furukawa, T. Nakamura, Y. Yamamoto, A. Kosaka, W. Jin, T. Fukushima and T. Aida, J. Phys. Soc. Jpn., 2008, 77, 034710.

5 A. Bashir, A. Heck, A. Narita, X. Feng, A. Nefedov, M. Rohwerder, K. Mullen, M. Elstnerb and C. Woll, Phys. Chem. Chem. Phys., 2015, 17, 21988-21996.

6 H. Huang, C.-E. Chou, Y. Che, L. Li, C. Wang, X. Yang, Z. Peng and L. Zang, J. Am. Chem. Soc., 2013, 135, 16490-16496.

7 X. Feng, M. Liu, W. Pisula, M. Takase, J. Li and K. Mullen, Adv. Mater., 2010, 20, 2684-2689.

8 T. Mori, Y. Kikuzawa and H. Takeuchi, Org. Electron., 2008, 9, 328-332.

9 X. Zhang, X. Jiang, K. Zhang, L. Mao, J. Luo, C. Chi, H. S. O. Chan and J. Wu, J. Org. Chem., 2010, 75, 8069-8077.

10 X. Feng, W. Pisula and K. Müllen, Pure Appl. Chem., 2009, 81, 2203-2224.

11 H.-W. Ip, C.-F. Ng, H.-F. Chow and D. Kuck, J. Am. Chem. Soc., 2016, 138, 13778-13781.

12 R. W. Miller, S. E. Averill, S. J. V. Wyck and A. C. Whalley, J. Org. Chem., 2016, 81, 12001-12005.

13 J. Liu, S. Osella, J. Ma, R. Berger, D. Beljonne, D. Schollmeyer, X. Feng and K. Mullen, J. Am. Chem. Soc., 2016, 138, 8364-8367.

14 M. Ball, Y. Zhong, Y. Wu, C. Schenck, F. Ng, M. Steigerwald, S. Xiao and C. Nuckolls, Acc. Chem. Res., 2015, 48, 267-276. 
15 J. Luo, X. Xu, R. Mao and Q. Miao, J. Am. Chem. Soc., 2012, 134, 13796-13803.

16 H. Arslan, F. J. Uribe-Romo, B. J. Smith and W. R. Dichtel, Chem. Sci., 2013, 4, 3973-3978.

17 T.-A. Chen and R.-S. Liu, Chem. - Eur. J., 2011, 17, 8023-8027.

18 A. Narita, X.-Y. Wang, X. Feng and K. Muellen, Chem. Soc. Rev., 2015, 44, 6616-6643.

19 B. Schuler, S. Collazos, L. Gross, G. Meyer, D. Pérez, E. Guitián and D. Peña, Angew. Chem., Int. Ed., 2014, 126, 9150-9152.

20 Q. Zhang, H. Peng, G. Zhang, Q. Lu, J. Chang, Y. Dong, X. Shi and J. Wei, J. Am. Chem. Soc., 2014, 136, 5057-5064.

21 P. Kovacic and F. W. Koch, J. Org. Chem., 1963, 28, 1864-1867.
22 P. Kovacic and M. B. Jones, Chem. Rev., 1987, 87, 357-379 and references therein.

23 B. Alameddine, R. S. Anju, F. Al-Sagheer and T. A. Jenny, New J. Chem., 2016, 40, 10363-10370.

24 B. Alameddine, A. Rice, T. A. Jenny and C. Luscombe, ChemistryOpen, 2015, 4, 453-456.

25 A. Fechtenkoetter, K. Saalwachter, M. A. Harbison, K. Müllen and H. W. Spiess, Angew. Chem., Int. Ed., 1999, 38, 3039-3042.

26 T. E. Barder, S. D. Walker, J. R. Martinelli and S. L. Buchwald, J. Am. Chem. Soc., 2005, 127, 4685-4696.

27 B. Alameddine, M. Schindler, S. Martin-Caba and T. A. Jenny, Synthesis, 2012, 1928-1934. 